\title{
Genome sequencing, assembly, annotation and analysis of Staphylococcus xylosus strain DMB3-Bh1 reveals genes responsible for pathogenicity
}

Gurwinder Kaur ${ }^{1 \dagger}$, Amit Arora ${ }^{1 \dagger}$, Sathyaseelan Sathyabama², Nida Mubin², Sheenam Verma², Shanmugam Mayilraj ${ }^{{ }^{*} \neq}$ and Javed N. Agrewala $2^{2^{*}}$

\begin{abstract}
Background: Staphylococcus xylosus is coagulase-negative staphylococci (CNS), found occasionally on the skin of humans but recurrently on other mammals. Recent reports suggest that this commensal bacterium may cause diseases in humans and other animals. In this study, we present the first report of whole genome sequencing of $S$. xylosus strain DMB3-Bh1, which was isolated from the stool of a mouse.

Results: The draft genome of S. xylosus strain DMB3-Bh1 consisted of 2,81,0255 bp with G+C content of 32.7 mol\%, 2623 predicted coding sequences (CDSs) and 58 RNAs. The final assembly contained 12 contigs of total size 2,81,0255 bp with N50 contig length of 4,37,962 bp and the largest contig assembled measured 7,61,338 bp. Further, an interspecies comparative genomic analysis through rapid annotation using subsystem technology server was achieved with Staphylococcus aureus RF122 that revealed 36 genes having similarity with S. xylosus DMB3-Bh1. 35 genes encoded for virulence, disease and defense and 1 gene encoded for phages, prophages and transposable elements.

Conclusions: These results suggest co linearity in genes between S. xylosus DMB3-Bh1 and S. aureus RF122 that contribute to pathogenicity and might be the result of horizontal gene transfer. The study indicates that $S$. xylosus DMB3-Bh1 may be a potential emerging pathogen for rodents.
\end{abstract}

Keywords: Coagulase-negative staphylococci, Staphylococcus aureus, CDSs, Rapid annotation using subsystem technology (RAST), EzTaxon, Virulence, Disease and defense

\section{Background}

Genus Staphylococcus was initially proposed by Ogston [1]. Later on emended by Rosenbach [2]. At present, the genus consists of 49 species and 26 sub-species (http:// www.bacterio.net/staphylococcus.html). Till date, 35

*Correspondence: mayil@imtech.res.in; javed@imtech.res.in

${ }^{\dagger}$ Gurwinder Kaur, Amit Arora are first authors, equal contributors

‡Shanmugam Mayilraj and Javed N. Agrewala contributed equally to this work

${ }^{1}$ Microbial Type Culture Collection and Gene Bank (MTCC), CSIR-Institute of Microbial Technology, Sector 39-A, Chandigarh 160036, India

2 Immunology Laboratory, CSIR-Institute of Microbial Technology, Sector 39-A, Chandigarh 160036, India species are whole genome sequenced, assembled and annotated some of these are: Staphylococcus aureus strain N315 [3], Staphylococcus carnosus strain TM 300 [4], Staphylococcus epidermidis strain ATCC 1228 [5], Staphylococcus haemolyticus strain JCSC 1435 [6], Staphylococcus lugdunensis strain HKU09-01 [7], Staphylococcus pseudointermidus strain ED 99 [8], Staphylococcus saprophyticus strain ATCC 15305 [9], Staphylococcus warneri strain SG 1 [10], Staphylococcus xylosus strain SMQ-121 [11] and Staphylococcus cohnii subsp. cohnii [12]. Various members of the genus Staphylococcus are commensals and inhabitant of the skin and upper respiratory tracts of mammals [13]. S. aureus is the most 
common species of Staphylococcus which causes Staphylococcal infections, mainly in the immunocompromised hosts [14]. S. xylosus persists as a commensal on the skin of mammals but occasionally in humans. S. xylosus is ubiquitous and can be noticed in diverse niches viz. polluted water, fodder, soil surface, etc. [15]. Since, S. xylosus is increasingly becoming infectious along with the other staphylococci, therefore it is imperative to explore the genome of this commensal [16-20]. In the public domain totally seven strains of $S$. xylosus have been sequenced at genome level, in which three strains are completely sequenced whereas four strains were having draft genome sequence. Although previous studies in the literature have performed genome annotation and analysis of S. xylosus, but a deep analysis on the pathogenicity of this organism obtained from the genomic information through next generation sequencing (NGS) was absent in the literature. Therefore, we generated the draft genome of $S$. xylosus strain DMB3- Bh1 which was isolated from the stool of mouse. Although S. xylosus have been reported to be isolated from several sources, we isolated this strain from mouse stool sample during the process of screening several other isolates from mouse stool in order to study mouse gut microbiota. Further a function based comparative genomic analysis of $S$. xylosus strain DMB3-Bh1 with S. aureus strain RF-122 and S. xylosus strain SMQ-121 were performed using RAST server that revealed genes contributing to pathogenicity in S. xylosus strain DMB3-Bh1.

\section{Results}

\section{Strain identification by $16 \mathrm{~S}$ rRNA gene sequencing}

An almost complete 16S rRNA gene sequence of the strain (1477 bp) was obtained and phylogenetic analysis showed that the strain DMB3-Bh1 should be assigned in the genus Staphylococcus. The strain DMB3-Bh1 showed highest degree of similarity with S. xylosus strain ATCC $29971^{\mathrm{T}}$ (100\%) followed by Staphylococcus saprophyticus subsp. saprophyticus strain ATCC $15305^{\mathrm{T}}$ (99.80\%), Staphylococcus saprophyticus subsp. bovis strain GTC $843^{\mathrm{T}}(98.66 \%)$. The phylogenetic relationship among the species of genus Staphylococcus in which strain DMB3Bh1 formed a separate branch along with S. xylosus (Fig. 1). The snp count of the 16S rRNA gene present in the genome of DMB3-Bh1 is 1, its having only a single copy of $16 \mathrm{~S}$ rRNA gene.

\section{Genomic features of strain DMB3-Bh1}

The draft genome of S. xylosus strain DMB3-Bh1 consisted of $28,10,255$ bp with $\mathrm{G}+\mathrm{C}$ content of $32.7 \mathrm{~mol} \%$, 2623 predicted CDSs and 58 RNAs. The molar G+C content of the genus Staphylococcus ranges from 32.40 to $32.76 \%$. The final assembly contained 12 contigs of total size $28,10,255 \mathrm{bp}$ with N50 contig length of 4,37,962 bp and the largest contig assembled measured 7,61,338 bp. The strain showed forty-nine virulence genes and two genes encoding sub-category adhesions as revealed by RAST annotation server. No OMP's were detected in the genome of strain DMB3-Bh1. Genome sequencing project information is given in Table 1. Genome Statistics is given in Table 2. Sub-system distribution of S. xylosus strain DMB3-Bh1 is depicted in Fig. 2 based on RAST annotation server. The graphical circular map of the genomes is shown in Fig. 3.

\section{Genes involved in virulence, disease and defense}

Whole genome annotation of Staphylococcus xylosus strain DMB3-Bh1 in RAST server revealed a total of 1657 genes. Forty-nine genes encoded for virulence, disease and defense. Some of the genes coding functional proteins are fibronectin binding protein, chaperonin, two component response regulator BceR, bacitracin export ATP binding protein BceA, bacitracin export permease protein $B c e B$, dihydrofolate synthase, folylpolyglutamate synthase, amidophosphoribosyl transferase, acetyl-coenzyme A, carboxyl transferase beta chain, colicin $\mathrm{V}$ production protein, tRNA pseudouridine synthase A, copper translocating $\mathrm{P}$ type ATPase, MerR family, multidrug resistance protein, membrane component of multidrug resistance system, TetR family regulator protein of MDR cluster, mercuric ion reductase, TcaR arsenical resistance protein ACR3, arsenic efflux pump protein and arsenate reductase (Fig. 4). Numbers of genes associated with the general cluster of orthologous groups (COG) functional categories are given in Table 3.

\section{Phages, prophages, transposable elements, plasmids}

A total of 7 protein coding genes were identified in this class. These include, phages DNA binding protein, phage terminase large subunit, phage portal protein, phage tail length tape-measure protein, $\mathrm{HNH}$ homing endonuclease and zinc metalloproteinase precursor (Fig. 5).

\section{Function based comparative genomic analysis}

Function based comparative genomic analysis of $S$. xylosus strain DMB3-Bh1, newly sequenced S. xylosus strain SMQ-121 and S. aureus strain RF122 was achieved with RAST server. A total of 67 protein coding genes were obtained among genomes of S. xylosus strain DMB3-Bh1, S. xylosus strain SMQ-121 and S. aureus strain RF122. Out of the several classes, the prime focus was narrowed down to only two classes (1) virulence, disease and defense; (2) phages, prophages, transposable elements, plasmids in all the three strains. A comparative analysis of these two classes showed 42 genes were present in these three strains. Forty-one genes were common in 


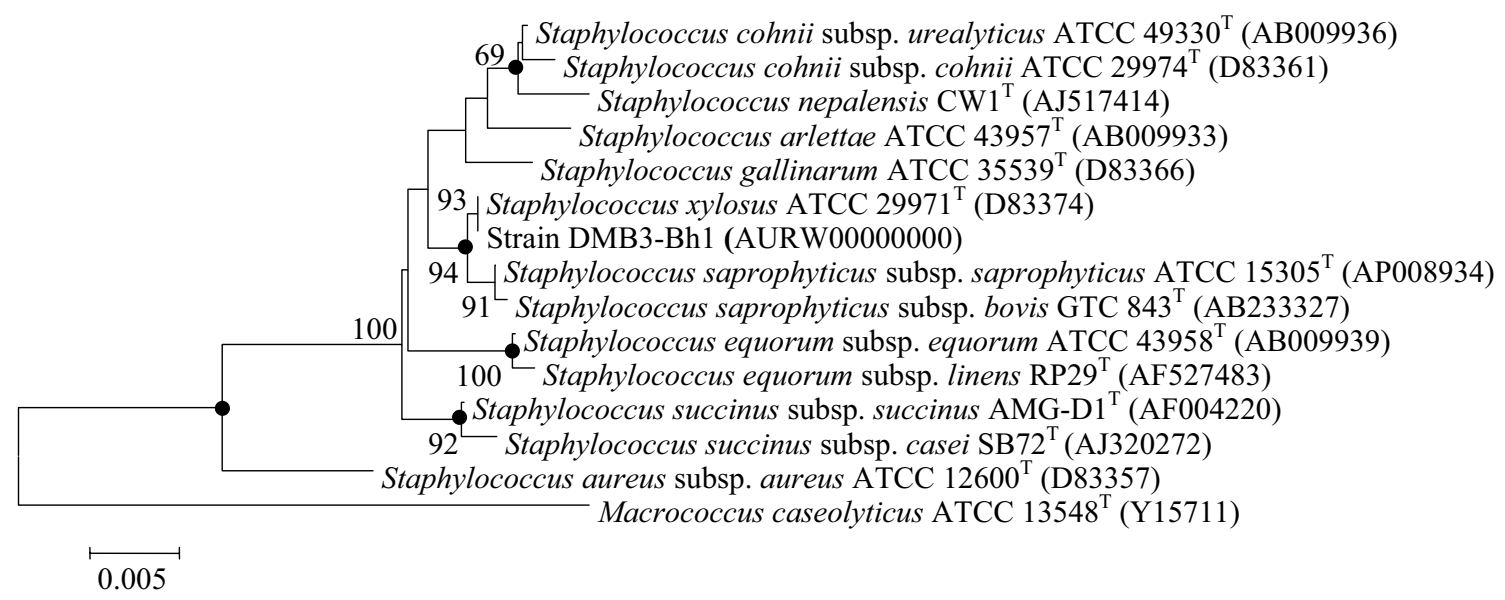

Fig. 1 Phylogenetic tree. Neighbour-joining tree based on 16S rRNA gene sequences showing the phylogenetic relationship between Staphylococcus xylosus strain DMB3-Bh1 and related members of the genus Staphylococcus. Macrococcus caseolyticus ATCC $13548^{\top}$ was used as an out-group. Bootstrap values (expressed as percentages of 100 replications) greater than $50 \%$ are given at nodes. Branches recovered in the maximum parsimony and likelihood algorithms are indicated by filled circles. GenBank accession numbers are given in the parentheses

Table 1 Genome sequencing project information

\begin{tabular}{lll}
\hline MIGS ID & Property & Term \\
\hline MIGS-31 & Finishing quality & High quality draft \\
MIGS-28 & Libraries used & Paired end $\sim 30 \mathrm{bp}$ \\
MIGS-29 & Sequencing platforms & Illumina HiSeq 1000 \\
MIGS-31.2 & Sequencing coverage & 1145.46x \\
MIGS-30 & Assemblers & CLC Bio Workbench v6.0.4 \\
MIGS-32 & Gene calling method & Prodigal 1.4, GenePRIMP \\
\hline & Genbank ID & AURW01000000 \\
& NCBI project ID & PRJNA210599 \\
\hline MIGS-13 & Project relevance & Virulence factor, phages \\
\hline
\end{tabular}

Table 2 Genome statistics

\begin{tabular}{lrl}
\hline Attribute & Value & \% of Total \\
\hline Genome size (bp) & $2,810,255$ & \\
DNA coding region (bp) & $2,364,894$ & 84.15 \\
DNA G+C content (bp) & 2681 & 84.46 \\
Total genes & 58 & 0.31 \\
RNA genes & 2 & 0.16 \\
rRNA operons & 2623 & \\
Protein-coding genes & 560 & 10.47 \\
Pseudo genes & 2121 & 73.99 \\
Genes with function prediction & 181 & 7.28 \\
Genes in paralog clusters & 2474 & 92.28 \\
Genes assigned to COGs & 8 & 0.28 \\
Genes with transmembrane helices & &
\end{tabular}

class virulence, disease and defense, where as one gene was common in class phages, prophages, transposable elements and plasmids. The sequence similarity of the 42 potential virulence factors were determined and it ranges from 30 to $98 \%$ for strains RF122/DMB3-Bh1 and 71-100\% for strains SMQ121/DMB3-Bh1. Detailed similarity values of the virulence genes among the strains were in Additional file 1: Table S1. Common genes present in both the classes were: Chaperonin (heat shock protein 33), Fibronectin-binding protein, Bacitracin export ATPbinding protein BceA, Bacitracin export permease protein BceB, DNA-directed RNA polymerase beta' subunit (EC 2.7.7.6), Translation initiation factor 3, Arsenic efflux pump protein, Beta-lactamase (EC 3.5.2.6), Choloylglycine hydrolase (EC 3.5.1.24), cobalt-zinc-cadmium resistance protein, Transcriptional regulator, MerR family. Remarkably five genes contributing pathogenicity were exclusively present in our strain S. xylosus strain DMB3Bh1 and were absent in S. xylosus strain SMQ-121. These were Fosfomycin resistance protein FosB, Phage portal protein, Phage tail length tape-measure protein, Phage tail length tape-measure protein and Phage terminase large subunit. The Venn-diagram revealed the number of shared genes in the genome of two closely related strains of genus Staphylococcus i.e. S. xylosus strain DMB3-Bh1 and $S$. aureus strain RF122. Out of a total of 1498 COG classes, 1294 were common between S. xylosus strain DMB3-Bh1 and S. aureus strain RF122. These 1294 COGs corresponded to 19 unique COG classes (B, C, D, E, F, G, H, I, J, L, M, N, O, P, Q, R, S, T, U) (Fig. 6). 13 hypothetical genes found in the genome of strain DMB3-Bh1. One 


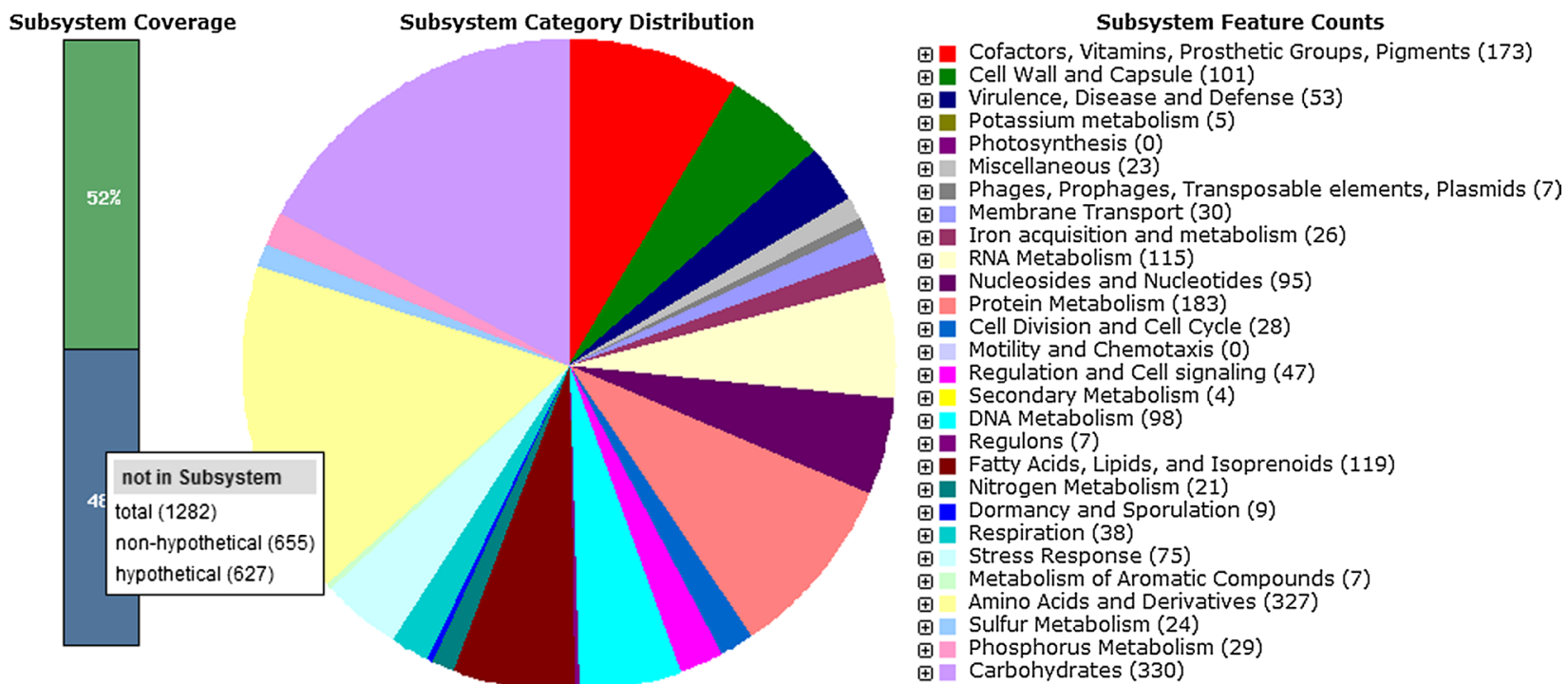

Subsystem Coverage Subsystem Category Distribution

Subsystem Feature Counts

(I) Cofactors, Vitamins, Prosthetic Groups, Pigments (173)

(1) Cell Wall and Capsule (101)

$\rightarrow$ Virulence, Disease and Defense (53)

$\rightarrow$ Potassium metabolism (5)

Photosynthesis (0)

$\boxplus$ Miscellaneous (23)

Phages, Prophages, Transposable elements, Plasmids (7)

(7) Membrane Transport (30)

Iron acquisition and metabolism (26)

$\pm \quad$ RNA Metabolism (115)

(I) Nucleosides and Nucleotides (95)

Protein Metabolism (183)

- Cell Division and Cell Cycle (28)

$\boxplus$ Cell Division and Cell Cycle (28)

\pm Motility and Chemotaxis (0)

$\boxplus$ Regulation and Cell signaling (47)

(I) Secondary Metabolism (4)

(I) DNA Metabolism (98)

$\boxplus$ Regulons (7)

Fatty Acids, Lipids, and Isoprenoids (119)

Nitrogen Metabolism (21)

Dormancy and Sporulation (9)

$\Phi$ Respiration (38)

$\boxplus$ Respiration (38)

$\boxplus \quad$ Stress Response (75)

\pm Metabolism of Aromatic Compounds

(1) Sulfur Metabolism (24)

$\rightarrow$ Phosphorus Metabolism (29)

Carbohydrates (330)

Phages, Prophages, Transposable elements, Plasmids-

Virulence, Disease and Defense - - 倣

Fig. 2 Sub-system distribution. Sub-system distribution of S. xylosus DMB3-Bh1 based on RAST annotation

hand, multiple genes can be associated with a single COG class and on the other, a single COG identifier can have multiple class associations. S. xylosus strain DMB3-Bh1 had 87 COG identifiers annotated with multiple classes. As these multiple classes are closely related to similar types of biological process, we verified their biological roles by employing the KEGG database [21] and using the corresponding KEGG IDs (KO) to inspect the respective pathways (data not shown).

Further, a comparative genomic analysis strategy was also performed with the virulence genes of $S$. aureus RF122 obtained from VFDB (http://www.mgc.ac.cn/ cgi-bin/VFs/genus.cgi?Genus=Staphylococcus), which showed the absence of autolysin, toxins and type-VII secretion systems in genome of S. xylosus DMB3-Bh1 compared to S. aureus RF122.

\section{Discussion}

This study reports the whole genome sequencing of $S$. xylosus strain DMB3-Bh1 isolated from the mouse stool. The annotated draft genome of strain DMB3-Bh1 was 28, 10,255 bp in size with 2,623 protein coding sequences. It has 400 subsystems, in which two major classes' virulence disease and defense; phages, prophages, transposable elements, plasmids were analyzed for genes responsible for infection in mice. This suggests that $S$. xylosus strain DMB3-Bh1 is a potential mouse pathogen and can cause zoonotic diseases. Pathways involved in the pathogenicity and host resistance in S. xylosus strain DMB3-Bh1 could be analyzed for novel targets for designing antimicrobial drugs and vaccines. Further, a comparative genomic analysis was performed among S. xylosus strain DMB3-Bh1, S. xylosus strain SMQ-121 and $S$. aureus strain RF122 that revealed 42 genes were present in all the three strains responsible for infection in the host. This demonstrates that there could be frequent acquisition of virulent factors by $S$. xylosus strain DMB3Bh1 from S. xylosus strain SMQ-121 and S. aureus strain RF122, through lateral genetic transfer (LGT) via the mechanisms of transduction, transformation and/ or conjugation. The exogenous genetic material can be integrated into the recipient genome through genetic recombination also. In Staphylococcus, phage-mediated conjugation is one of the more common mechanisms of genetic transfer, in which the presence of bacteriophages can increase the adhesiveness of the bacterial cell surface and therefore assist in the conjugative transfer of genetic materials between two organism [22]. There were five genes not present in S. xylosus strain SMQ-121 but present in S. xylosus strain DMB3-Bh1.This signifies that the strain DMB3-Bh1 has more pathogenic potential as compared to S. xylosus strain SMQ-121. The commensal S. xylosus is zoonotic agent and can be a threat to human beings [23]. The current study envisages that its genome sequence information will have significant implications in developing novel drug targets drugs and vaccines. 


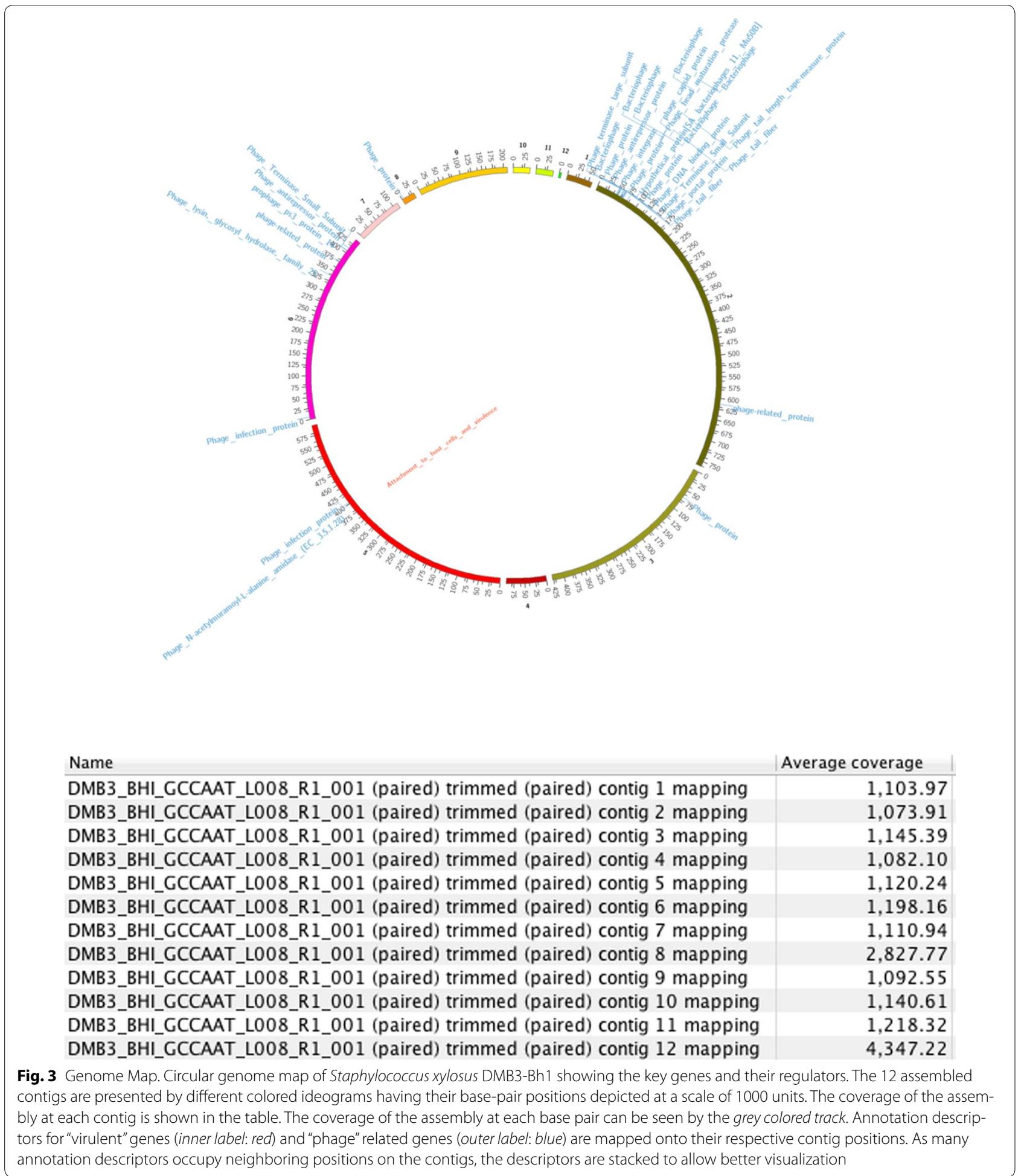

\section{Conclusions}

In the present study we have provided a genomic insight into the genome of S. xylosus strain DMB3-Bh1. We were able to map the virulence profile of this organism using in silico approaches. Several putative factors contributing pathogenicity were found in strain DMB3-Bh1 when a comparative pathogenomics approach was employed with other reference strain of genus Staphylococcus 


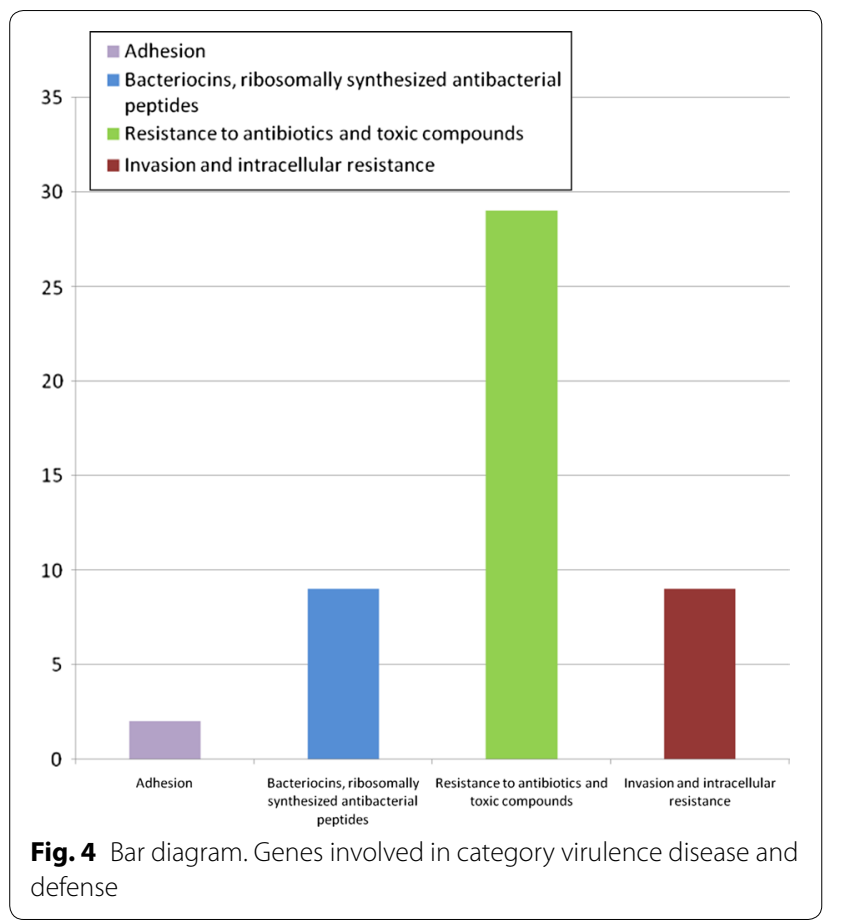

from publically available databases. Though the data is a preliminary report on the virulence profile of $S$. xylosus strain DMB3-Bh1, such data adds to the repository of virulent pathogens and acts as a building platform for the development of novel therapeutics against emerging pathogens.

\section{Methods}

\section{Isolation of bacterial strains and growth conditions}

S. xylosus strain DMB3-Bh1 was isolated from the stool sample of BALB/c. The stool was homogenised in sterile PBS (1X) and centrifuged at $1000 \mathrm{rpm}$ for $2 \mathrm{~min}$ to remove debris. Supernatant was serially diluted and plated on tryptone soya agar (TSA, HiMedia, Mumbai, India) and later incubated at $37{ }^{\circ} \mathrm{C}$ for $36 \mathrm{~h}$ to isolate pure bacterial colonies. Microscopic examination was done to examine cell morphology, motility and sporulation. Cells of strain DMB3-Bh1 are Gram-positive, $0.7-1.0 \mu \mathrm{m}$ in size (Fig. 7). Different biochemical features were tested. Strain DMB3-Bh1 was positive for urease, nitrate reduction and catalase. Negative for tween 80 and aesculin hydrolysis; oxidase. Acid production was also determined by using different sugars and the strain is positive for glucose, fructose, maltose, xylose, lactose, mannitol, arabinose and negative for cellobiose, galactose, salicin, adonitol, fucose and raffinose. Capable of growing between 20 and $42{ }^{\circ} \mathrm{C}$ and tolerant up to $8.0 \% \mathrm{NaCl}$. Classification and general features of strain DMB3-Bh1 are accordance with the MIGS recommendations shown in Table 4.
Table 3 Number of genes associated with the general COG functional categories

\begin{tabular}{llll}
\hline Code & Value & \% age & Description \\
\hline J & 149 & 6.7 & Translation, ribosomal structure and biogenesis \\
A & 0 & 0.0 & RNA processing and modification \\
K & 129 & 5.9 & Transcription \\
L & 115 & 5.3 & Replication, recombination and repair \\
B & 0 & 0.0 & Chromatin structure and dynamics \\
D & 28 & 1.3 & Cell cycle control, mitosis and meiosis \\
Y & 0 & 0.0 & Nuclear structure \\
V & 32 & 1.5 & Defense mechanisms \\
T & 133 & 6.1 & Signal transduction mechanisms \\
M & 119 & 5.5 & Cell wall/membrane biogenesis \\
N & 75 & 3.5 & Cell motility \\
Z & 0 & 0.0 & Cytoskeleton \\
W & 0 & 0.0 & Extracellular structures \\
U & 46 & 2.1 & Intracellular trafficking and secretion, and \\
& & \multicolumn{3}{c}{ vesicular transport } \\
O & 70 & 3.2 & Posttranslational modification, protein turnover, \\
& & \multicolumn{4}{c}{ chaperones } \\
C & 142 & 6.5 & Energy production and conversion \\
G & 113 & 5.2 & Carbohydrate transport and metabolism \\
E & 252 & 11.6 & Amino acid transport and metabolism \\
F & 65 & 3.0 & Nucleotide transport and metabolism \\
H & 99 & 4.6 & Coenzyme transport and metabolism \\
I & 44 & 2.0 & Lipid transport and metabolism \\
P & 125 & 5.8 & Inorganic ion transport and metabolism \\
Q & 31 & 1.4 & Secondary metabolites biosynthesis, transport \\
& & & and catabolism \\
R & 243 & 11.2 & General function prediction only \\
S & 161 & 7.4 & Function unknown \\
- & 565 & 22.5 & Not in CoGs \\
\hline & & &
\end{tabular}

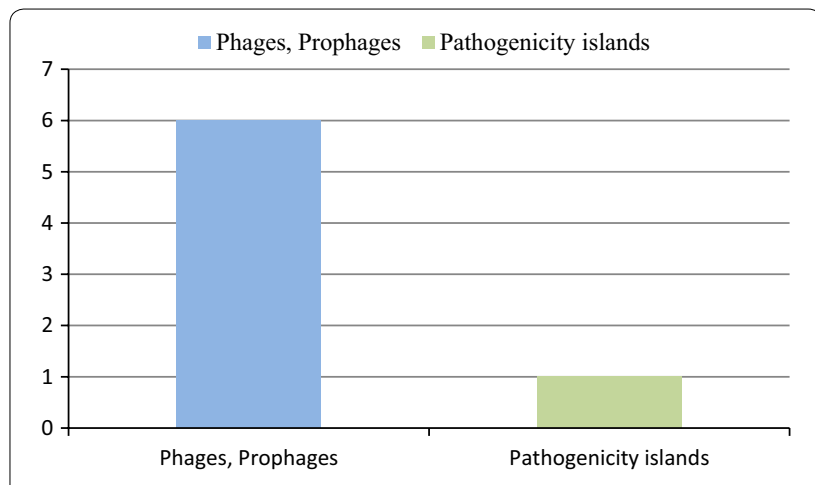

Fig. 5 Bar diagram. Genes involved in category phages, prophages, transposable elements, plasmids

Strain identification by $16 \mathrm{~S}$ rRNA gene sequencing Strain DMB3-Bh1 was identified by $16 \mathrm{~S}$ rRNA gene sequencing. Genomic DNA was extracted using Zymo 


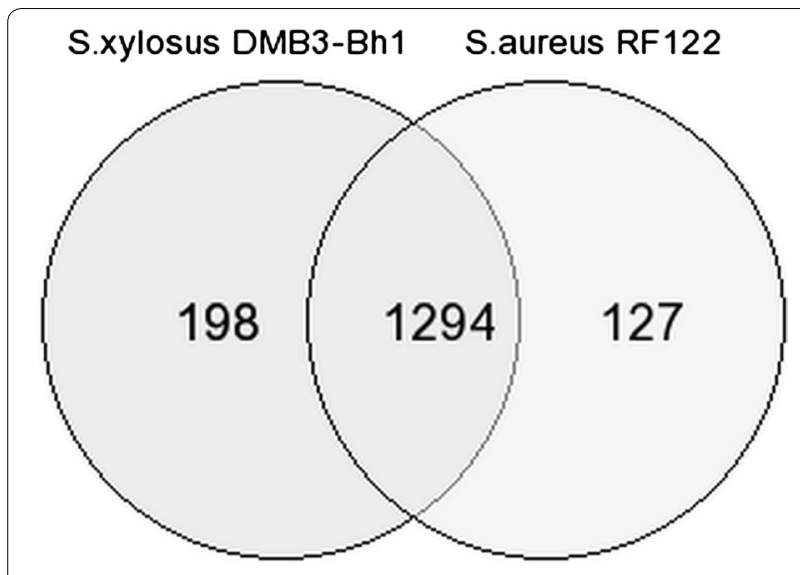

Fig. 6 Venn-diagram. Venn-diagram depicting the intersections of protein sets associated with the general COG functional categories

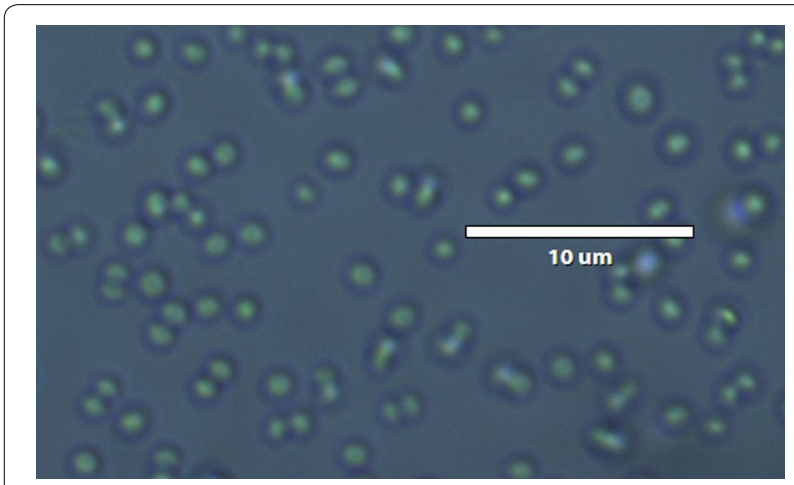

Fig. 7 Microscopic image. Microscopic image of strain DMB3-Bh1

Research kit, according to manufacturer's instructions (Zymo Research Corporation, Irvine, CA). 27f (5'-AG AGTTTGATCCTGGCTCAG-3') and 1500r (5'-AGAAA GGAGGTGATCCAGCCA-3') universal eubacterial primers specific for $16 \mathrm{~S}$ rRNA gene were used for genomic DNA amplification. The amplified product was separated using agarose gel (1\%) and finally purified using a QIAquick gel extraction kit (Qiagen, Stockach, Germany). Forward primers, 8-27f, 357f (5'-CTCCTACGGGAGGCAGCAG-3'), 704f (5'-TAGCG GTGAAATGCGTAGA-3'), 1114f (5'-GCAACGAGCG CAACC-3') and reverse primers 685r (5'-TCTACGCATT TCACCGCTAC-3'), 1110r (5'-GGGTTGCGCTCGTT G-3') and 1500r (Escherichia coli numbering system) were used for amplification of the purified PCR product [24].

\section{Phylogenetic analysis of strain DMB3-Bh1}

Phylogenetic neighbor identification and the computation of pairwise 16S rRNA gene sequence similarities were achieved using the EzTaxon server and alignment
Table 4 Classification and general features of Staphylococcus xylosus strain DMB3-Bh1 accordance with the MIGS recommendations

\begin{tabular}{|c|c|c|c|}
\hline MIGS ID & Property & Term & Evidence code \\
\hline & Current clas- & Domain Bacteria & [34] \\
\hline & sification & Phylum Firmicutes & {$[35-37]$} \\
\hline & & Class Bacilli & {$[38,39]$} \\
\hline & & Order Bacillales & {$[40,41]$} \\
\hline & & $\begin{array}{l}\text { Family Staphylo- } \\
\text { coccaceae }\end{array}$ & {$[38,42]$} \\
\hline & & $\begin{array}{l}\text { Genus Staphylo- } \\
\text { coccus }\end{array}$ & {$[2,40,43]$} \\
\hline & & $\begin{array}{l}\text { Species Staphylo- } \\
\text { coccus xylosus }\end{array}$ & {$[40]$} \\
\hline & & Strain DMB3-Bh1 & Present study \\
\hline & Gram stain & Positive & IDA \\
\hline & Cell shape & Coccus & IDA \\
\hline & Motility & Non-motile & IDA \\
\hline & Sporulation & Non-sporulating & IDA \\
\hline & $\begin{array}{l}\text { Temperature } \\
\text { range }\end{array}$ & $20-45^{\circ} \mathrm{C}$ & IDA \\
\hline & $\begin{array}{l}\text { Optimum tem- } \\
\text { perature }\end{array}$ & $37^{\circ} \mathrm{C}$ & IDA \\
\hline & Salinity & $3 \% \mathrm{NaCl}$ & IDA \\
\hline \multirow[t]{3}{*}{ MIGS-22 } & $\begin{array}{l}\text { Oxygen } \\
\text { requirement }\end{array}$ & $\begin{array}{c}\text { Facultatively } \\
\text { anaerobic }\end{array}$ & IDA \\
\hline & Carbon source & Glucose, fructose & IDA \\
\hline & Energy source & Fructose, trehalose & IDA \\
\hline MIGS-6 & Habitat & Mouse faecal & IDA \\
\hline MIGS-15 & $\begin{array}{l}\text { Biotic relation- } \\
\text { ship }\end{array}$ & Free living & IDA \\
\hline \multirow[t]{3}{*}{ MIGS-14 } & Pathogenicity & Non pathogenic & IDA \\
\hline & Biosafety level & 1 & [44] \\
\hline & Isolation & $\begin{array}{l}\text { From mouse faecal } \\
\text { sample }\end{array}$ & IDA \\
\hline MIGS-4 & $\begin{array}{l}\text { Geographic } \\
\text { location }\end{array}$ & Chandigarh,India & IDA \\
\hline MIGS-5 & $\begin{array}{l}\text { Sample collec- } \\
\text { tion time }\end{array}$ & 9th,October 2012 & IDA \\
\hline $\begin{array}{l}\text { MIGS-4.1 MIGS- } \\
4.2\end{array}$ & $\begin{array}{l}\text { Latitude-lon- } \\
\text { gitude }\end{array}$ & $\begin{array}{l}30.7660^{\circ} \mathrm{N} \\
76.7754^{\circ} \mathrm{E}\end{array}$ & IDA \\
\hline MIGS-4.3 & Depth & Unknown & IDA \\
\hline MIGS-4.4 & Altitude & About sea level & IDA \\
\hline
\end{tabular}

Evidence codes-IDA inferred from direct assay (first time in publication), TAS traceable author statement (i.e., a direct report exists in the literature); If the evidence code is IDA, then the property was observed by one of the authors or an expert mentioned in the acknowledgements

was performed using MEGA version 6.0 [25, 26]. The neighbor-joining, maximum parsimony and maximum likelihood algorithms were used to construct phylogenetic trees. Bootstrap analysis was carried out to assess the confidence limits of the branching. 


\section{Genome sequencing, assembly and annotation}

The genome of $S$. xylosus strain DMB3-Bh1 was sequenced using a standard run of Illumina HiSeq 1000 sequencing technology at c-CAMP by Next Generation Genomic Facility (Bengaluru, India http://www.ccamp. res.in). The genome of strain DMB3-Bh1 formed a total of 2,91,86,504 paired-end reads [paired distance (insert size) $\sim 330 \mathrm{bp}$ ] of $101 \mathrm{bp}$. The data was preprocessed to trim and remove low quality sequences using CLC Bio Workbench v6.0.4 (CLC Bio, Aarhus, Denmark). A total of 2,90,47,554 high quality, vector filtered reads ( 1145 times coverage) were employed for assembly (at word size of 45 and bubble size of 98). The genome coverage was $1145.46 \times$ and calculated using formula coverage $=($ read count $\times$ read length $) /$ total genome size. Final draft genome was used for genome annotation employing RAST server [27] and RNAmmer 1.2 server [28]. The graphical circular map of the genomes was made by [29]. COG analysis was performed using the Reversed Position Specific BLAST (RPS BLAST using NCBI COG version $2 / 2 / 2011$ ) [30] on the prokaryotic protein database with e-value of 0.001. MS Excel was used to compare the output COG ids between different strains. [31]. The Venn-diagram was made by using [32]. For comparative genomic analysis, the annotated genes were extracted from RAST server into an excel table and manually compared for genomic features. [33].

\section{Sequence data access}

This Whole Genome Shotgun project has been deposited at DDBJ/EMBL/GenBank under the accession AURW00000000. The version described in this paper is the first version, AURW01000000.ftp://ncbi. nlm.nih.gov/genomes/ASSEMBLY_REPORTS/All/ GCF_000467225.1.assembly.txt.

\section{Additional file}

Additional file 1: Table S1. Sequence similarity of 42 potential virulence factors between strains RF122/DMB3-Bh1 and SMQ121/DmB3-Bh1.

\section{Abbreviations \\ CNS: coagulase-negative staphylococci; CDSs: coding sequences; RAST: rapid annotation using subsystem technology; COG: cluster of orthologous groups.}

\section{Authors' contributions}

Performed experiments: GK, AA, SS, NM and SV. Planned and executed experiments analyzed data and wrote manuscript: SM and JNA. All authors read and approved the final manuscript.

\section{Acknowledgements}

We would like to thank Mr. Malkit Singh for his excellent technical assistance. We are also grateful to Mr. R. Girish Nair for critical reading of the manuscript.

\section{Competing interests}

The authors declare that they have no competing interests.

\section{Availability of data and materials}

Further work is going on for the time being we don't want to share data. This Whole Genome Shotgun project has been deposited at DDBJ/EMBL/GenBank under the accession AURW00000000. The version described in this paper is the first version, AURW01000000.

\section{Consent of publication}

Consent of all the authors has been obtained.

\section{Ethical clearance}

The study was ethically approved by the Institutional Biosafety Committee (Ref/IBSC/2012-2/09) and Institutional Animal Ethics Committee (IAEC 13/01) of the CSIR Institute of Microbial Technology, Chandigarh, India.

\section{Funding}

The project "Human Microbiome" (BSC 0119) is financially supported by the Council of Scientific and Industrial Research, New Delhi, India. The article bears IMTECH communication number 007/2014.

Received: 29 August 2016 Accepted: 1 November 2016 Published online: 08 November 2016

\section{References}

1. Ogston A. Micrococcus poisoning. J Anat Physiol. 1883;17:24-58.

2. Rosenbach FJ. Microorganismen bei den Wund-Infections-Krankheiten des Menschen. Wiesbaden: J.F. Bergmann; 1884. p. 1-122.

3. Kuroda M, Ohta T, Uchiyama I, Baba T, Yuzawa H, Kobayashi I, Cui L, Oguchi A, Aoki K, Nagai Y, Lian J, Ito T, Kanamori M, Matsumaru H, Maruyama A, Murakami H, Hosoyama A, Mizutani-Ui Y, Takahashi NK, Sawano T, Inoue R, Kaito C, Sekimizu K, Hirakawa H, Kuhara S, Goto S, Yabuzaki J, Kanehisa M, Yamashita A, Oshima K, Furuya K, Yoshino C, Shiba T, Hattori M, Ogasawara N, Hayashi H, Hiramatsu K. Whole genome sequencing of methicillin-resistant Staphylococcus aureus. Lancet. 2001;21:1225-40.

4. Rosenstein R, Nerz C, Biswas L, Resch A, Raddatz G, Schuster SC, Götz F. Genome analysis of the meat starter culture bacterium Staphylococcus carnosus TM300. Appl Environ Microbiol. 2009;75:811-22.

5. Zhang YQ, Ren SX, Li HL, Wang YX, Fu G, Yang J, Qin ZQ, Miao YG, Wang WY, Chen RS, Shen Y, Chen Z, Yuan ZH, Zhao GP, Qu D, Danchin A, Wen YM. Genome-based analysis of virulence genes in a non-biofilmforming Staphylococcus epidermidis strain (ATCC 12228) Mol. Microbiol. 2003:49:1577-93

6. Takeuchi F, Watanabe S, Baba T, Yuzawa H, Ito T, Morimoto Y, Kuroda M, Cui L, Takahashi M, Ankai A, Baba S, Fukui S, Lee JC, Hiramatsu K. Whole-genome sequencing of Staphylococcus haemolyticus uncovers the extreme plasticity of its genome and the evolution of human-colonizing staphylococcal species. J Bacteriol. 2005;187:7292-308.

7. Tse H, Tsoi HW, Leung SP, Lau SK, Woo PC, Yuen KY. Complete genome sequence of Staphylococcus lugdunensis strain HKU09-01. J Bacteriol. 2010;192(5):1471-2.

8. Ben-Zakour NL, Bannoehr J, van-den Broek AH, Thoday KL, Fitzgerald JR. Complete genome sequence of the canine pathogen Staphylococcus pseudintermedius. J Bacteriol. 2011;193:2363-4.

9. Kuroda M, Yamashita A, Hirakawa H, Kumano M, Morikawa K, Higashide M, Maruyama A, Inose Y, Matoba K, Toh H, Kuhara S, Hattori M, Ohta T. Whole genome sequence of Staphylococcus saprophyticus reveals the pathogenesis of uncomplicated urinary tract infection. Proc Natl Acad Sci USA. 2005:102(37):13272-7.

10. Cheng VW, Zhang G, Oyedotun KS, Ridgway D, Ellison MJ, Weiner JH. Complete Genome of the solvent-tolerant Staphylococcus warneri Strain SG1. Genome Announc. 2013;1 (2):e00038.

11. Labrie SJ, Haddad LE, Tremblay DM, Plante PL, Wasserscheid J, Dumaresq J, Dewar K, Corbeil J, Moineau S. First complete genome sequence of Staphylococcus xylosus, a meat starter culture and a host to propagate Staphylococcus aureus phages. Genome Announce. 2014;2(4):e00671.

12. Hu X, Li A, Lv L, Yuan C, Guo L, Jiang X, Jiang H, Qian G, Zheng B, Guo J, Li L. High quality draft genome sequence of Staphylococcus cohnii subsp. cohnii strain hu-01. Stand Genomic Sci. 2014;9:755-62. 
13. Kloos WE. Natural populations of the Genus Staphylococcus. Annu Rev Microbiol. 1980;34:559-92.

14. Christoph K. Nabera Staphylococcus aureus Bacteremia: epidemiology, pathophysiology, and management strategies. Clin Infect Dis. 2009:48:231-7.

15. Dordet-Frisoni E, Géraud D, Cécilia D, Araujo Régine T, Sabine L. Genomic diversity in Staphylococcus xylosus. Appl Environ Microbiol. 2007;73:7199-209.

16. Tselenis-Kotsowilis AD, Koliomichalis MP, Papavassiliou JT. Acute pyelonephritis caused by Staphylococcus xylosus. J Clin Microbiol. 1982;16:593-4.

17. Conrad SA, West BC. Endocarditis caused by Staphylococcus xylosus associated with intravenous drug abuse. J Infect Dis. 1984;149:826-7.

18. Bradfield JF, Wagner JE, Boivin GP, Steffen EK, Russell RJ. Epizootic fatal dermatitis in athymic nude mice due to Staphylococcus xylosus. Lab Anim Sci. 1993:43:111-3.

19. Bingel SA. Pathology of a mouse model of $x$-linked chronic granulomatous disease. Contemp Top Lab Anim Sci. 2002;41:33-8.

20. Koksal F, Yasar H, Samasti M. Antibiotic resistance patterns of coagulasenegative Staphylococcus strains isolated from blood cultures of septicemic patients in Turkey. Microbiol Res. 2009;164:404-10.

21. Kanehisa M, Sato Y, Kawashima M, Furumichi M, Tanabe M. KEGG as a reference resource for gene and protein annotation. Nucleic Acids Res. 2016;44:D457-62.

22. Lacey RW. Evidence for two mechanisms of plasmid transfer in mixed cultures of Staphylococcus aureus. J Gen Microbiol. 1980;1 19:423-35.

23. Siqueira JF Jr, Lima KC. Staphylococcus epidermidis and Staphylococcus xylosus in a secondary root canal infection with persistent symptoms: a case report. Aust Endod J. 2002;28:61-3.

24. Mayilraj S, Saha P, Suresh K, Saini HS. Ornithinimicrobium kibberense sp. nov., isolated from the Himalayas, India. Int I Syst Evol Microbiol. 2006;56:1657-61.

25. Kim O, Cho YJ, Lee K, Yoon SH, Kim M, Na H, Park SC, Jeon YS, Lee JH, Yi H, Won S, Chun J. Introducing EzTaxon-e: a prokaryotic 16S rRNA Gene sequence database with phylotypes that represent uncultured species. Int J Syst Evol Microbiol. 2012;62:716-21.

26. Tamura K, Stecher G, Peterson D, Filipski A, Kumar S. MEGA6: molecular evolutionary genetics analysis version 6.0. Mol Biol Evol. 2013;30:2725-9.

27. Aziz RK, Bartels D, Best AA, DeJongh M, Disz T, Edwards RA, Formsma K, Gerdes S, Glass EM, Kubal M, Meyer F, Olsen GJ, Olson R, Osterman AL, Overbeek RA, McNeil LK, Paarmann D, Paczian T, Parrello B, Pusch GD, Reich C, Stevens R, Vassieva O, Vonstein V, Wilke A, Zagnitko O. The RAST Server: rapid annotations using subsystems technology. BMC Genom. 2008:9:75-89.

28. Lagesen K, Hallin P, Rodland EA, Staerfeldt HH, Rognes T, Ussery DW. RNAmmer: consistent and rapid annotation of ribosomal RNA genes. Nucleic Acids Res. 2007:35:3100-8.

29. Circular map: CIRCOS, Krzywinski M, Schein J, Birol I, Connors J, Gascoyne R, Horsman D. Circos: an information aesthetic for comparative genomics. Genome Res. 2009;19:1639-45.
30. Altschul SF, Gish W, Miller W, Myers EW, Lipman DJ. Basic local alignment search tool. J Mol Biol. 1990;215:403-10.

31. Markowitz VM, Mavromatis K, Ivanova N, Chen IM, Chu K, Kyrpides N. Expert Review of functional annotations for microbial genomes. Bioinformatics. 2009:25:2271-8. doi:10.1093/bioinformatics/btp393.

32. Venn Diagram: This was generated using $R$ programming language. http://cran.r-project.org/.

33. Nair G, Gurwinder K, Indu K, Nitin KS, Sudeep KM, Srikrishna S, Arunanshu B, Divya D, Javed NA, Shanmugam M. Genome mining and comparative genomic analysis of five coagulase-negative Staphylococci (CNS) isolated from human colon and gall bladder. J Data Mining Genom Proteom. 2016;7:2.

34. Woese CR, Kandler O, Wheelis ML. Towards a natural system of organisms: proposal for the do-mains Archaea, Bacteria, and Eucarya. Proc Natl Acad Sci USA. 1990;87:4576-9.

35. Gibbons NE, Murray RGE. Proposals concerning the higher taxa of bacteria. Int J Syst Bacteriol. 1978;28:1-6.

36. Garrity GM, Holt JG. The road map to the man-ual. In: Garrity GM, Boone DR, Castenholz RW, editors. Bergey's Manual of Systematic Bacteriology, vol. 1. 2nd ed. Springer: New York; 2001. p. 119-69.

37. Murray RGE. The higher taxa, or, a place for everything...? In: Holt JG, editor. Bergey's manual of systematic bacteriology. Baltimore: The Williams and Wilkins Co.; 1984. p. 31-4.

38. ferrivorans Hallberg A. List of new names and new combinations previously effectively, but not validly, published. List no. 132. Int J Syst Evol Microbiol. 2010;60:469-72.

39. Ludwig W, Schleifer KH, Whitman WB Class. Class I Bacilli class nov. In: De Vos P, Garrity G, Jones D, Krieg NR, Ludwig W, Rainey FA, Schleifer KH, Whitman WB, editors. Bergey's manual of systemat-ic bacteriology, vol. 3. 2nd ed. Springer: New York; 2009. p. 19-20.

40. Skerman VBD, McGowan V, Sneath PHA. Ap-proved lists of bacterial names. Int J Syst Bacteriol. 1980;30:225-420.

41. Prévot, A.R. In: Hauderoy P, Ehringer G, Guillot G, Magrou. J., Prévot AR, Rosset D, Urbain A (eds). Dictionnaire des Bactéries Pathogènes, Second Edition, Masson et Cie, Paris. 1953;1-692.

42. Schleifer KH, Bell JA. Family VIII. Staphylococcaceae fam. nov. In: DeVos P, Garrity G, Jones D, Krieg NR, Ludwig W, Rainey FA, Schleifer KH, Whitman WB, editors. Bergey's manual of systematic bacteriology. 2nd ed. New York: Springer; 2009.

43. Baird-Parker AC, Genus II. Staphylococcus Rosenbach 1884, 18. In: Buchanan RE, Gibbons NE, editors. Bergey's manual of determinative bacteriology. 8th ed. Baltimore: The Williams and Wilkins Co.; 1974. p. 483-9.

44. BAuA. Classification of bacteria and archaea in risk groups. http://www. baua.de TRBA 466; 2010.

\section{Submit your next manuscript to BioMed Central and we will help you at every step:}

- We accept pre-submission inquiries

- Our selector tool helps you to find the most relevant journal

- We provide round the clock customer support

- Convenient online submission

- Thorough peer review

- Inclusion in PubMed and all major indexing services

- Maximum visibility for your research

Submit your manuscript at www.biomedcentral.com/submit
BioMed Central 